\title{
Aspecto Estructural y Temático de los Poemas de Alejandra Pizarnik
}

\author{
Manjola Brahaj (Halili)
}

PhD. In Literature, University of Prizren "Ukshin Hoti"

Doi:10.19044/esj.2019.v15n17p81 ～URL:http://dx.doi.org/10.19044/esj.2019.v15n17p81

\section{Resumen}

Cuando se pasa de un período a otro en la creatividad de Pizarnik, se nota un cambio gradual en el aspecto formal y estructural de la misma. Este cambio crea la impresión de que la poeta nunca demuestra estar satisfecha con la búsqueda continua de nuevas formas estructurales en su poesía. Esta investigación se concentra precisamente en este aspecto.

Aspecto que se puede explorar y realizar sólo a través de la observación del texto, es decir, con métodos textuales; semióticos y estructurales. El análisis se hará con la intención de observar las formas de los poemas. Asimismo, servirán de gran ayuda los métodos comparativos.

Para entender más fácilmente los poemas de Pizarnik, también nos ocuparemos de los siguientes temas: el miedo, el lenguaje, la ansiedad, el amor, la muerte, el asesinato, la infancia, la inocencia, etc.

Palabras claves: estructura poética, lenguaje, texto poético, aspecto formal, silencio. 


\title{
The Structural and Thematic Aspect of Alejandra Pizarnik's Poems
}

\author{
Manjola Brahaj (Halili)
}

$\mathrm{PhD}$. In Literature, University of Prizren "Ukshin Hoti"

\begin{abstract}
When we pass from one period to another of Pizarnik's creativity, we notice a gradual change of the formal and structural aspect in it. This change in the search for a new structure leaves the impression that this poet is never complacent with the form of her poetry and continues to search. In this surveying we are going to focus precisely on this aspect and on the way it changes. This aspect that we have decided to explore in this scientific work is done only through the observation of the text, which means, with the textual methods; semiotics and structuralism, with the intention of analyzing the forms of the poems, where the comparative methods will also help us. The easiest way to understand this poet is to study the topics which she writes about, among them we can mention; fear, language, anxiety, love, death, murder, childhood, innocence, etc.
\end{abstract}

Keywords: poetic structure, language, poetic text, formal aspect, theme, etc.

\section{Introducción}

Hay dos razones por las cuales hemos elegido a esta escritora para la investigación en concreto. La primera razón se debe a la peculiaridad de sus poemas. Su creatividad es muy especial y original motivo por el que no se puede confundir con ningún otro poeta o escritor.

La otra razón se relaciona con el hecho de que la traducimos al albanés y sus poemas han resultado muy atractivos para los lectores. Además, para los lectores albaneses y su literatura es algo completamente nuevo, ya que este tipo de poesía no está escrita ni reconocida en dicha literatura. Parece como si el misterio de sus poemas atrajese a los lectores de todas las épocas y países.

El objeto de la investigación será principalmente el análisis de los textos de los poemas de Alejandra Pizarnik conocidos con el título "La completa elaborada", que no son, realmente, el trabajo completo de esta escritora, sino algunos de los principales volúmenes de su poesía y prosa. Dicho en otras palabras, que no incluyen diarios ni otros géneros de su creatividad. 


\section{La metodología del estudio}

Por lo que se refiere al método con el que hemos realizado el análisis, se trata principalmente de métodos textuales. Métodos que se enfocan especialmente en el texto, en este sentido hemos logrado analizar los elementos que construyen el texto para ver las diferencias y la originalidad. Este tipo de análisis se hará con la intención de analizar las formas de los poemas, y como estas cambian cuando se pasa de un período de su creatividad a otro , o dicho de otra manera consisten en su mayoría en métodos formalistas.

Asimismo, para realizar este trabajo nos vedrán de gran ayuda los métodos comparativos. Con los que secontrastarán diferentes períodos y diferentes volúmenes de la creatividad poética de Pizarnik. La intención es ver las formas de sus poemas y, de ese paso, entender por qué cambian y por qué esta autora experimenta tanto con sus versos.

También se emplearán los textos teóricos que se relacionan con la antigua retórica (Barthes, 1982) que nos proporcionan las herramientas adecuadas para el análisis retórico y métrico de la poesía.

\section{En busca de la estructura perfecta}

De la lectura, de la traducción y del análisis de los poemas de esta escritora se nota el cambio en el aspecto estructural de los volúmenes poéticos y, también, el cambio entre sus poemas. Relacionado con este último, no sólo en el aspecto estructural y formal, sino también en lo visual. Pizarnik, también, escribió un género de poesía, el que hoy en día llamamos poesía visual. Poemas que dan su significado simbólico incluso a través de la imagen creada por la forma en la que se ordenan y organizan palabras y versos. Porque la poesía puede significar muchas cosas al mismo tiempo y, en pocas palabras, con su estructura típica los poetas de cada tiempo han prestado especial atención a sus versos, la longitud, la posición de las palabras y su conexión. La formación de esta estructura constituye lo que de otra manera se llama forma. Su preservación y la continuidad de una lógica similar de creación, pero la naturaleza inherente de esta estructura crea cohesión en la creación. Manteniendo la cohesión y la organización interna de la poesía ha hecho que sus estructuras externas funcionen y transmitan significados simbólicos semánticos, ya que la continuidad y la preservación de las estructuras lingüísticas internas en lo que se llama microestructura hacen posible la formación y la posición de la macroestructura poética.En consecuencia, algunas de las características que su poesía recibe durante esta búsqueda, se verán en las siguientes etapas. 


\subsection{Los versos libres y la espontaneidad visual}

El volumen de poesía que se titula "La tierra más ajena" comienza con una parte caracterizada por una amplia y suelta extensión de versos. Los poemas no están organizados según el modelo clásico de versatilidad, solo en algunos casos encontramos estrofas de tres o seis versos, eso hace que se sienta la espontaneidad de los mismos y, también, se vea como imagen, donde el ritmo poético disminuye y los versos se rompen, para ser coherentes con la idea. Como se ve en el volumen "Terra más ajena", en el poema "Reminiscencias."

y el tiempo estranguló mi estrella

cuatro números ríen en volteretas desabridas

muere uno

nace uno

y el tiempo estranguló mi estrella... (Pizarnik, p.5)

El ritmo de la poesía en los poemas de Pizarnik se realiza por la rima interna asonancia, aliteración y repeticiones. (Pla, pp. 5-6)

Consecuentemente, no tenemos un ritmo que sea visible y que sea el resultado de usar la rima, sino un ritmo que se siente más y se oculta dentro de los poemas. Unos poemas fragmentarios, pero que dicen mucho y abren muchas puertas a la interpretación, como expresa Benelli Basso:

El carácter profético en el que se ampara el hablante lírico para hablar del proceso de búsqueda del yo esencial adquiere formas o estructuras variadas, pese a que no recurre a la métrica como opción rítmica. Los poemas se organizan en su mayoría en versos sin puntuación, dejando en suspenso el inicio o el final; es decir, una escritura fragmentada, es decir, cuyos inicios y finales no siempre están marcados ortográficamente y dejando abierta la posibilidad de interpretación.

Pero también se ve en el siguiente caso.

mis pupilas negras sin ineluctables chispitas mis pupilas grandes polen lleno de abejas mis pupilas redondas disco rayado mis pupilas graves sin quiebro absoluto mis pupilas rectas sin gesto innato mis pupilas llenas pozo bien oliente mis pupilas coloreadas agua definida mis pupilas sensibles rigidez de lo desconocido mis pupilas salientes callejón preciso mis pupilas terrestres remedos cielinos mis pupilas oscuras piedras caídas. (Pizarnik, p. 10)

Por esa razón, los poemas de Pizarnik no se pueden analizar de acuerdo con "todos los elementos de la estructura clásica de versatilidad, incluyendo el metro, las rimas", etc. (Raud, pp. $1-2$ ). 
Porque también esta poeta, como gran parte de los poetas contemporáneos, recurre de alguna manera a la poesía tradicional, y no usa muchas figuras retóricas para convencer o crear una lectura retórica (Barthes, 1982, p.77), su poesía es una expresión natural interior, aunque pensamos que no todos los poetas pueden hacer este tipo de creación. Sólo aquellos que escapan de la tradición, por el camino natural en la procuración de ellos mismos, así que apoyamos la opinión de Culler cuando dice: "no tengo una opinión firme sobre cómo regular o exitosamente debería decirse que los poetas de los siglos XX y XXI escaparon a la tradición lírica.” (Culler. 2015) creando la poesía que se denominó moderna y que produce un arte muy distinto a lo tradicional como lo afirma también Friedrich:

De artículos alemanes, franceses, españoles e ingleses acerca de la lírica moderna entresacamos las siguientes fórmulas, insistiendo en que fueron empleadas no peyorativa, sino descriptivamente: desorien-_ tación, disolución de lo corriente, sacrificio del or- den, incoherencia, fragmentarismo, reversibilidad, estilo en series, poesía despoetizada, relámpagos destructores, imágenes cortantes, choque brutal... ( Friedrich, p.25)

Esta poeta no mide estrictamente sus versos y tampoco se preocupa en donde poner énfasis, sea una vocal u otra. Sus líneas son libres y están separadas de las rígidas reglas, lo que la hace, estructuralmente, más flexible y poéticamente más original. Así que ella se parece más a los escritores que buscan, crean y investigan cosas nuevas para elaborar versos, para formar su estilo único, porque su búsqueda es en primer lugar una búsqueda del lenguaje, y como afirma en su estudio Cohen: "El lenguaje poético es un hecho de estilo. El poeta no habla como los demás. Su lenguaje es anormal, y esta anormalidad es la que asegura un estilo." (Cohen, p.4)

En estilo de Pizarnik la longitud de los versos cambia tanto, como cambia la forma y la sensación que estos poemas procuran durante la lectura. En este tipo de organización, el lenguaje que se utiliza y sobre todo con la sensación que causan estos poemas crean la idea, que forman parte de un solo poema, sea con los versos largos o cortos, una forma de extraña ansiedad y un silencio oscuro. Con este tipo de versos Pizarnik nos hace sentir la persistencia en la búsqueda de algo, un tipo de ansiedad constante por una respuesta, una forma de salir y convertirse en algo que no le pertenece... salvarse. Como dice Daza:

En la poesía y el humor pizarnikianos nada es azar y ambas escrituras se presentan como una respuesta, a la intensa angustia metafísica que la acompaña durante toda su vida, que la empuja a reflexionar en torno al lenguaje a través del mismo lenguaje. (Daza, p.2) 
No sólo en el primer volumen, sino también en toda su obra de creación, encontraremos poemas que van desde los seis versos hasta más de veinte y otros que se reducirán a solo tres. Técnicas y elecciones también basadas en la situación y la idea que transmite la poesía. Sus largos poemas parecen estar relacionadas con la ansiedad, el dolor, la soledad y algo que la separa de algún lugar, para caer infinitamente, en una sucesión lenta, dolorosa...de manera continua. Pero lo que la poeta tiene con tres, cuatro o seis versos máximos y es asombroso leer, con la brevedad y la idea que siguen para hacerte pensar por mucho tiempo, para encontrar la esencia del próximo dilema que esta autora ha planteado. Entonces, al ver en un análisis horizontal, cuando nos movemos de un volumen a otro o de un poema a otro dentro del mismo volumen, vemos cambios en la forma estructural de la organización del poema, y cambios en la versatilidad. Por eso podemos decir que Pizarnik sigue siendo una poeta que intenta y juega con sus versos, para traer siempre formas nuevas y sorprendentes. Este cambio es esencial en términos de construcción pero que hace que los poemas de Pizarnik sean difíciles de traducir a otro idioma, porque se corre el riesgo de perder el efecto simbólico transmitido a través de la forma de los poemas.

Sus poemas son un reflejo de su vida, son un espejo en el que se ve la cara oscura y a menudo triste y enojada de Pizarnik, creando la idea clara, que esta persona como poeta, realmente se ha convertido en parte del papel. El personaje y el yo poético ha tomado las características del autor y parece más vivo y tangible que el propio autor. Se convierte en la verdad más viva a través de sus versos, como escribe Paz en el prólogo del libro "Árbol de Diana": "sus poemas no tienen ni una sola partícula de mentira".

De esta forma construye su misma alma única e inseparable, crea sus poemas creando su propia figura indestructible, haciendo un sacrificio existencial. Estas elecciones estructurales y conceptuales "dibujan el perfil de una femineidad no convencional, poseedora de una pasión extrema, capaz de "escribir con su cuerpo el cuerpo del poema"( Moratiel, 31 diciembre).

Parece que en sus poemas se encuentre una participación total de su inconsciencia-que escribe poemas-, así como su profundidad incontrolable que la hace completamente franca, íntima y tan verdadera en sus versos. Haremos referencia a Culler sobre este asunto, el cual dice: "Creo que sería un error suponer, que los reclamos de poemas líricos siempre deben tratarse como relativos a la experiencia de un individuo " (Giusti, 2017) porque la conciencia o experiencia del poeta no siempre hablará en sus poemas. La poesía, como dijimos en el caso de Pizarnik, puede ser el producto de lo inconsciente o como dice Giusti: "El poema se resuelve en el testimonio de la memoria involuntaria ocasional, construida sobre una serie de imposibilidades y deficiencias mutuas, ahora como entonces" (Giusti, 86). 
El contenido de su poesía lo confirma al igual que la estructura y la forma de su texto son las opuestas. ¿Qué es lo contrario? Si nos detenemos y analizamos la estructura poética, las palabras y su posición en sus poemas, parece que en este tipo de poesía, más que cualquier otra cosa hable la voz del lenguaje, parece ser obra y creación del lenguaje, como dice el investigador Remo Cesarini: "el lenguaje mismo ha escrito poesía" (Cesarini, p. 80)

Por eso podemos decir que esto se refleja en la organización formal de los versos, organización el cual habla de otro tipo de poesía, como dice Friedrich: “ "...al llegar al otro tipo de poesía, aparecen también otros atributos, casi exclusivamente negativos y que por otra parte se refieren cada vez menos al contenido y cada vez más a la forma" (Friedrich, p. 23).

Esta organización formal habla de un flujo natural y suelto de ellos, por lo que prevalecen los poemas con clasificaciones sucesivas de versos libres, mientras que los poemas que apuntan a una imagen más concreta y simbólica aparecen menos en el primer volumen pero van creciendo y prevaleciendo en el segundo y tercer volumen. La poeta De-poema en poema, continúa su búsqueda de la excelencia formal, tratando de dar imágenes de la caída, pérdida...pero nunca del fin, y esta idea se da, no sólo de manera significativa sino también a través de la imagen. Sus poemas son creaciones que muestran el viaje, hablan del final, pero nunca lo dan. Estamos tratando aquí de estructuras de poesía abiertas, que invitan al lector a convertirse en la última parte, para construir un fin desde su propia perspectiva. Es una opción espontánea, libre, pero atractiva para el lector, un texto lírico que se abre al mundo y que debe comunicarse como una ventana desde la cual se puede ver y observar el mundo como cada uno de nosotros lo desea. Las estructuras abiertas del texto lírico son pocas, ya que esta estrategia se usa más en la prosa de la modernidad y más allá en la literatura, es por eso que este proceso sigue siendo como fue expresado por Bernardelli:

Diferente, de todo lo que es diferente, es en cambio el caso del texto lírico, que se presenta como una estructura abierta lógicosemántica, o sea que se caracteriza por un grado insuficiente de determinación de las coordenadas de locución y las unidades de significado, que lo componen para el propósito de una relación comunicativa correcta y satisfactoria. (Bernardelli, p. 169)

Como se ve en los siguientes versos, la estructura es el resultado del lenguaje y la imagen que sigue es la forma de estructura abierta e inacabada. el vino es como un llanto desolado que humedece mi juventud frente a tus besos que otra deglute el vino es el elixir que pulveriza los pestilentes deseos de 
mi cuerpo que

aletea gimiendo frente a tu efigie de

sombra amodorrada. (Pizarnik, p. 31)

Los poemas de Pizarnik hablan y transmiten significados...sensaciones, no sólo con las palabras, sino también con su forma. Un caos interno, oscuro y espantoso, se organiza de una manera extraña. Está claro que la poeta experimentó con las formas organizativas y estilísticas, su poesía. Haciendo que se parezca mucho a un tipo de poesía llamada, "poesía experimental de vanguardias" (Cesarini, p. 12) pero este tipo de poesía, como escribe A. Pizarnik, no va a los extremos formales y destructivos a las que llegan los vanguardistas en la poesía. En su poesía se encuentran pruebas y experimentos, queriendo demostrar que el experimento es algo natural para los poetas que siempre cambian y aportan innovación original. Siempre buscan y quieren ser refinados artísticamente. En sus poemas, vemos esta insistente búsqueda, no por experimentos provocativos o simplemente por el ruido, la aparición del escándalo como ocurre en la vanguardia, sino por la perfección poética interna en el discurso, donde se deletrea todo lo que tenía dentro de sí misma, sin ninguna barrera formal o estructural impuesta o dictada externamente. En el caso de Pizarnik, es su propio interior que dicta el camino de la investigación y el cambio, haciendo que la poesía se experimente como un proceso, no como una finalización. Como dice la investigadora Doria:

Porque la poesía es un proceso en el que el poeta busca y experimenta constantemente con la materia de la que parte: -la palabra-, la cual es imagen y sonido, al mismo tiempo que parte del contexto y está en permanente diálogo con las experiencias anteriores y presentes. En la poesía experimental verdadera la respuesta al pasado no es nunca una negación, sino una construcción hacia nuevos horizontes. (Doria, p. 47)

Y, para nosotros, eso es exactamente lo que hace a Pizarnik tan interesante y especial en su creatividad, porque ella crea en sus poemas a través de un lenguaje que selecciona, busca...y encuentra, pero parece que a menudo no está satisfecha. Y cuando eso sucede, no se detiene. Haciendo parecer que este lenguaje no es suficiente y su creatividad siempre está buscando no solo el cambio formal, sino también la perfección de la expresión del lenguaje. No le importa -lo que se haya escrito antes de ella- en este aspecto, habla con su voz y sus figuras, con actuaciones únicas y su voz original. Siendo, no solo "una exploradora" del lenguaje y del misterio" (Daza, p. 2), sino al mismo tiempo también-la forma y la estructura- que revela su mundo interior.

La característica esencial de esta búsqueda, hace organizar su caos existencial, pero quizás también la mejor manera posible de organizarlo, es la repetición. El poeta repite las palabras, al principio, al final y en el medio del 
los versos. Parece que a menudo se lo repite a sí misma, se encuentra y se enfrenta con el caos que rodea, su vida. Un caos lleno de ideas, miedos y dudas sobre el mundo. La vida, la existencia, el lenguaje, el amor y el yo, en su creatividad arman un caos filosófico, bello y meditativo, no solo por su poesía, sino también por lo que ella ha traído a la literatura mundial. Por eso, su espontaneidad organiza, visualmente el caos y las imágenes de sus poemas. Como se ve en el siguiente caso, donde la distribución de palabras da la impresión de un caos, pero en realidad es un caos organizado que permite no solo un tipo de lectura, sino muchas combinaciones y muchos sentidos al mismo tiempo.

escrito creatura en plegaria rabia contra la niebla

en contra

el la

crepúsculo opacidad

$$
\begin{aligned}
& \text { no quiero ir } \\
& \text { nada más } \\
& \text { que hasta el fondo }
\end{aligned}
$$

oh vida

oh lenguaje

oh Isidoro (Pizarnik, p. 371)

El cambio constante en la forma de escribir poesía, nos hace pensar que en su búsqueda, Pizarnik estaba constantemente insatisfecha, siempre buscando algo nuevo para cumplir lo que ella quería expresar, para traer frente al lector su mundo, su silencio, sus temores.

\subsection{Poema en prosa, búsqueda final.}

Los géneros intermedios se cultivaron por primera vez en el período de simbolismo y surrealismo en Francia, principalmente por poetas franceses; Sharl Bodler, Arthur Rimbau, Rene Char, etc. Los poemas en prosa y prosa poética dieron una visión diferente a la literatura, las divisiones clásicas y estrictas de géneros. Hicieron que coexistan de manera muy natural entre sí la poesía y la prosa. Muchos poetas se encontraron mejor en esta forma poética de expresión. Esta forma le daaba más seguridad y libertad y, además con esta forma existía la posibilidad de utilizar un rico vocabulario poético y un poderoso lenguaje figurativo que no impedía en absoluto, por al contrario, daba el poder artístico y expresivo a estas creaciones.

Por eso, como se ve claramente Pizarnik en su creatividad está influenciada por este período de la literatura. En la creatividad de esta poeta encontramos-obras de poemas en prosa-, aunque no en todas las obras, lo que nos da la impresión de que los límites de la poesía no eran suficientes para mostrar lo que sentía y experimentaba. Este tipo de prosa, que escribe 
Pizarnik, es una prosa llena de poesía muy íntima, con muchas características y similitudes con la poesía. De hecho solo el aspecto formal de la historia nos dice -terminológicamente que los llamemos poemas en prosa, ya que bien podrían llamarse poesías narrativas. En algunos casos, es similar a la naturaleza de los diarios íntimos, por la forma y la manera de confesión, pero el predominio de la figuratividad y la expresión poética hacen de esta parte de su creatividad un poema en prosa de tipo particular, muy similar a la del reconocido poeta francés Arthur Rimbau igual que en el caso siguiente:

Toda la noche escucho el llamamiento de la muerte, toda la noche escucho el canto de la muerte junto al río, toda la noche escucho la voz de la muerte que me llama. (Pizarnik, p. 210)

Por eso, para nosotros escribir en este género, una transición suave de la poesía al poema en prosa, íntima y muy parecida a la poesía, es un punto final en su investigación estructural. Porque esta transición "De los poemas breves y depurados de los dos libros anteriores, da paso a un poemario que salta a poemas de una prosa extensa en donde el yo se vuelca hacia lo fúnebre y lo sombrío" ( Gamboa, p. 90). Para nosotros es una búsqueda a la perfección y la expresividad a lo más grande posible, pero también a lo más poético posible. Así que a lo largo de los años, por ejemplo, cuando vamos a su volumen "El infierno musical" de 1971, la relación de la prosa con la poesía cambia a favor de la prosa. La prosa de esta escritora es feroz en su curso, incontrolada y sin estiramientos, parece ser todo el impulso de su ser, todas las dudas y ansiedades que apenas se han lanzado en esta forma de escritura amplia y rítmica, liberada y llena de sensaciones.

En este período las poesías son menores como número y completamente cortas, parece que la investigación formal ha llegado a su fin, ya que Pizarnik ha probado muchas formas y tipos de escritura y poesía moderna.

\section{La búsqueda temática}

En cuanto a los temas y preocupaciones que siguen a Alejandra Pizarnik en sus poemas, son muchos, pero todas en nuestra opinión son un reflejo de su vida y su creatividad poética, tan verdadera y sensible en cada uno de sus versos. Los temas cambian de una etapa a otra como lo han observado también otros investigadores, como Haydu el cual estudió la etapa en la cual la autora escribió el "Árbol de Diana." "Los temas principales que distinguimos en esta etapa y que serán: amor, infancia, naturaleza, muerte, lenguaje/silencio, y las distintas formas de tratar el "yo enunciativo", su manera de autoreferirse" (Haydu, p. 52).

Por eso su formación, la capacidad de observación y el juicio agudo que tenía sobre la realidad y el mundo que la rodeaba, han hecho que en su creatividad se encuentren algunos problemas y temáticas fundamentales 
como; la ansiedad existencial, el tiempo, el miedo, la muerte repetida, el amor, etc.

\subsection{La ansiedad existencial}

Es precisamente esta ansiedad existencial la que se convierte en el principal fuente de búsqueda y tratamiento de temas y motivos. Es su ser que busca la tranquilidad, procura encontrar un paraíso artificial, donde podrá hablar y su lengua será suficiente, donde las palabras no se suicidan. Esta búsqueda, hace posible pasar a través de estos puntos claves de la existencia y el cuerpo semántico-temático de sus poemas, ser una preocupación existencial con todos los elementos y sus componentes. Una búsqueda que no se para jamás, como afirma Barthes referiendose al escritor moderno:"el escritor ya no tiene pasiones, humores, sentimientos, impresiones, sino ese inmenso diccionario del que extrae una escritura que no puede pararse jamás" (Barthes, p. 70).

Esté diccionario del cual habla Barthes está muy relacionado precisamente con las pasiones, temores, humores y sentimientos del autor. Son estos que lo hacen brotar y no terminar nuca, cómo sucede en el caso de Pizarnik. Es esté diccionario el que hace que se escriban diferentes temas con muchas palabras originales e inrrepetibles.

De esta manera para esta poeta, siempre hay algo oculto detrás de sus palabras y formas, que simboliza su poesía, dejando en la superficie lo que ve como imágenes en su imaginación creativa; ocultando debajo de ellas, bajo la capa simbolizadoras los significados y otros mensajes, los temores y sus incertidumbres. Reminiscencias y tiempo, manifestaciones y existencia, el hombre y el universo, se comunican e interactúan para dar la atmósfera en la poesía de Alejandra como en el siguiente caso.

dos besos comunicantes de la visión de una existencia a otra existencia dos promesas gimientes de tremendas locuacidades ajenas dos promesas de no ser de sí ser de no ser dos sueños jugando la ronda del sino en derredor de un cosmos de champagne amarillo blanquecino dos miradas cerciorando la avidez de una estrella chiquita y el tiempo estranguló mi estrella cuatro números ríen en volteretas desabridas muere uno nace uno... (Pizarnik, p. 5 ) 


\subsection{El tiempo}

Es precisamente el tiempo que ha determinado el cambio y la transformación de esta existencia en otra cosa, el niño en su interior ya no es un niño. Y esta sigue siendo una de sus preocupaciones más insistentes, que a menudo aparecen en sus poemas. Parece que el tiempo roba a la autora y su esplendor, durante el paso del tiempo cambia y se transforma, pero de todos modos al final su esencia sigue siendo indestructible. El núcleo arquetípico de la existencia seguirá brillando de nuevo. Entonces, aunque la poeta sienta miedo y una guerra interna con el tiempo, nosotros pensamos que es precisamente esta guerra la que hace que el tiempo siga siendo, una de las preocupaciones temáticas más significativas. En sus poemas ella siente que ha ganado contra el tiempo. Existirá porque su alma es intemporal.

y el tiempo estranguló mi estrella

pero su esencia existirá

en mi intemporal interior

brilla esencia de mi estrella! (Pizarnik, p.6)

\subsection{El miedo}

Relacionados con el tiempo están los temores y las dudas. Estos son, también, motivos básicos del movimiento en la poesía, se puede observar que hay movimientos del miedo a la ansiedad, de la ansiedad a la existencia, de la existencia a lo profundo, a lo intemporal. En sus poemas hay dudas sobre esta existencia, por lo cual no quiere existir y por consecuencia, por causa de esta duda existencial nace el miedo. De ella, parece que un alma lírico no puede escapar, tampoco puede salvarse. Como se ve muy claro en los siguientes versos:

Que haré con el miedo?

Que haré con el miedo? (Pizarnk, pp. 72-73)

el infierno que la persigue, después de la pérdida de la inocencia. Parece que su interior está en una guerra constante, lo que hace que a menudo sienta miedo y también piense en la muerte. Los estudiosos de la literatura los llaman "poetas malditos" como menciona entre ellos Zapata diciendo que:

“...... pues el poeta "maldito" fue siempre el "poseído por la verdad", como lo escribió Robert Graves. Poetas como Trakl, Artaud, Bretón, Yeats, Pessoa, Daumal, Michaux, Celan, Paz, Eunice Odio, Pizarnik, entre otros, en nuestra época todavía encarnaron este ideal fáustico que hace que el "poeta maldito" nos hable de su infierno, de sus terrores, de su malestar, de su extravío para subrayar con ello la pérdida de un estado de gracia original, de una inocencia y una armonía primordiales, gracia, inocencia y armonía que a la postre, buscará siempre recuperar (Zapata, p. 94)" 
La preocupación y el doloroso sentimiento de que la infancia ha huido y ya no hay más inocencia, el temor de no ser más la misma persona y que probablemente lo que es no le guste más son los temores que nos hacen creer que tenemos aquí precisamente el caso del poeta maldito.

No le gusta sí misma porque se ha convertido en otra cosa, ha escapado de esa realidad y de lo que es. Y, aunque le tiene miedo al tiempo, ese miedo tiene su tiempo que vive en su interior como una conexión larga y trascendente.

\author{
el tiempo tiene miedo \\ el miedo tiene tiempo \\ el miedo \\ pasea por mi sangre \\ arranca mis mejores frutos \\ devasta mi lastimosa muralla \\ destrucción de destrucciones \\ sólo destrucción \\ y miedo \\ mucho miedo \\ miedo. (Pizarnik, p.41)
}

O como sucede en otro caso, cuando el tiempo se acaba, se consume solo en un momento, porque el momento es el que decide el curso general de los eventos y las cosas.

He consumado mi vida en un instante

La última inocencia estalló

Ahora es nunca o jamás

o simplemente fue. (Pizarnik, pp.72-73)

\title{
3.4. La muerte repetida
}

Aunque la muerte se piensa y se siente como una solución, el personaje poético parece morir varias veces, y la muerte como tema sigue siendo recurrente. A veces aparece en poemas y diferentes volúmenes de poesías, con diferentes formas y tamaños, haciendo sentir que en la muerte permanece la mayor preocupación y es al mismo tiempo el motivo más frecuente en su creatividad.

Su lucha interior se vuelve feroz en extremo, al ver la muerte como una solución y al mismo tiempo temerosa por lo que pueda suceder después.

$$
\begin{aligned}
& \text { ¿Cómo no me suicido frente a un espejo } \\
& \text { y desaparezco para reaparecer en el mar } \\
& \text { donde un gran barco esperaría } \\
& \text { con las luces encendidas? (Pizarnik, pp. } 72-73 \text { ) }
\end{aligned}
$$

Quizás esta frecuencia de escritura sobre el tema, habla del fin de la existencia física de la poeta, pero no nos detendremos en esta parte, ya que no es nuestro objetivo de trabajo, pero también se ha escrito mucho sobre este 
tema y el suicidio de la poeta. Para más información sobre este tema ver: $\underline{\mathrm{D}}$. Perez, Carlos. 2007.

Este tipo de observación que relaciona lo oscuro con la muerte, es parte de su estética creativa, por eso, también, encontramos motivos simbólicos de la noche, del silencio, de la sombra y de la oscuridad, que se repiten bastante, así la unión de estos dos, que surgen como motivos desde los cuales fluyen los pensamientos y versos.

\subsection{El amor}

Pero además de la muerte en la poesía de Pizarnik, no con menor frecuencia también viene el amor, haciendo que sea lo opuesto a esto, en sus versos ante la muerte es la vida, es el eros. Su poesía describe la conexión indestructible de dos opuestos los cuales conviven el uno con el otro desde siempre, Eros - Thanatos.

$$
\begin{aligned}
& \text { sí amor estás lejos como el mosquito } \\
& \text { sí! Ese que persigue a una mosquita junto } \\
& \text { al farol amarillo sucio que vigila bajo el } \\
& \text { cielo negro limpio esta noche angustiosa } \\
& \text { llena de dualismos" (Pizarnik, pp. 29-30) }
\end{aligned}
$$

Pero en otros casos, el amor parece ser la única luz y la única salvación, como una especie de viaje para alcanzar lo inmenso y la perfección. A través del simbolismo y de los detalles que crean el amor, se construye el viaje de salvamiento del yo poético (que es el personaje poético). En este tipo de poemas, no hay miedo, ni colores oscuros, ni sombras, haciéndonos entender el otro lado de la medalla temática en los poemas. Un eros que la salva espiritualmente, ante todo, y no es solo una llamada física o una necesidad de este tipo, su dirección es desde lo vulnerable-terrenal hacia el universo y la eternidad. Como en el siguiente caso:

$$
\begin{aligned}
& \text { Mi amor se amplía. } \\
& \text { Es un paracaídas perfecto. } \\
& \text { Es un clic que se exhala y } \\
& \text { su pecho se hace inmenso. } \\
& \text { Mi amor no ruge } \\
& \text { no clama } \\
& \text { no ruega } \\
& \text { no ríe. } \\
& \text { Su cuerpo es un ojo. } \\
& \text { Su piel es un mapamundi. (Pizarnik, p. 32) }
\end{aligned}
$$

\section{Conclusion}

Después de esta observación, hemos notado el cambio en el aspecto estructural de los volúmenes poéticos, pero también el cambio de registro de la poeta Alejandra Pizarnik. En sus poemas se refleja una búsqueda constante hacia la perfección de la expresión lingüística, que está estrechamente 
vinculada a la importancia y construcción formal - estructural de su poesía. Un tipo de poesía que enfatiza la innovación y la originalidad, no solo de la construcción formal sino también de lo visual. Pizarnik ha escrito el tipo de poesía que hoy llamamos visual, un ejemplo que hemos concretado en el artículo.

Su búsqueda estructural está esencialmente relacionada con el tema y el lenguaje con el cual realiza sus poemas. Por lo tanto, podemos decir que su búsqueda no es solo estructural, sino ante todo lingüística y poética porque como hemos analizado, al autor siempre está en busca de palabras únicas para expresar su mundo interior. Su búsqueda es una búsqueda que no tiene un final definido, ya que sus estructuras no dejan de cambiar, pero al mismo tiempo se dejan abiertas, divididas e implícitas, creando la idea de continuidad.

Toda la creación de esta poeta, tal como se enfatiza y analiza en el trabajo, ha pasado por un camino lleno de pruebas y experimentos continuos, de exploración interna, que la ha llevado desde la poesía a los poemas en prosa, para terminar en una prosa llena de una víva figuración, con una narración libre y impulsiva.

Esta variable ha hecho que la creación de Pizarnik no caiga en la monotonía o en repetición -ya que muchos poetas corren este peligro durante su vida creativa- pero ha generado y recreado formas, y al mismo tiempo ha tratado nuevas temas y motivos, integrales e inseparablemente vinculados a ellos. Todo eso lo ha realizado con la esencia y el método tan original de su creatividad.

También, podemos decir que los poemas de Pizarnik tratan y desarrollan temas muy específicos y originales. Anteriormente en la historia de la poesía no es que no hayan escrito otros escritores sobre la muerte, el amor o el tiempo, sino que es la forma en la que esta poeta observa y trata de relacionarlas, -una como causa y otra como consecuencia- la hace de manera original y no confundible con otros escritores. Eso hace, al mismo tiempo, que su mundo poético - temático, sea tan identificable...como la marca que deja de su pluma!.

\section{References:}

1. Bernardelli, Giuseppe. (2002), Il testo lirico, Vita e Pensiero, Milano.

2. Barthes, Roland. (1982), La antigua retórica, Trad. de Beatriz Dorritos, Ediciones Buenos Aires S.A, España.

3. Barthes, Roland. (1987), El susurro del lenguaje. Más allá de la palabra y la escritura, Trad. de Fernández, C. Paidós, Barcelona.

4. Benelli Basso, Cristián. Disponible en: https://www.monografias.com/trabajos53/poesia-alejandrapizarnik/poesia-alejandra-pizarnik2.shtml n.d 
5. Culler, Jonathan. (2015), The theory of the Lyric, Harvard University Press, USA.

6. Cohen, Jean. (1977), Estructura del lenguaje poético, Ed. Gredos, Madrid.

7. Cesarini, Remo. (2005), Il testo poetico, Il Mulino, Bologna.

8. Daza, Paulina. "Alejandra Pizarnik: poesía, prosa, humor y otros misterios." Disponible en: http://dx.doi.org/10.4067/S071804622016000200207 Atenea Concepcion, no.514, 2016, p. 2.

9. Doria, Glòria B. P. "Poesia contemporánea en el aula: experimentalidad, multimodalidad e interdisciplinariedad como formars de reflexión, creación y emoción", Valencia: Universidad Católica de Valencia. EDETANIA 49, 2016.

10. Friedrich, Hugo. (1959), Estructura de la lírica moderna, Traducción a español de Juan Petit, Editorial Seix Barral, S.A. Barcelona.

11. Giusti, Francesco. "Il cerchio che non chiude: forme della temporalità nella poesia

12. contemporanea", Napoli: FeDOA - Federico II University Press. SigMa - Rivista di Letterature comparate, Teatro e Arti dello spettacolo, 2017.

13. Giusti, Federico. "The Lyric in Theory: A Conversation with Jonathan Culler". Disponible en: https://lareviewofbooks.org/article/the-lyricin-theory-a-conversation-with-jonathan-culler_Los Angeles Review of Books, (27/05/ 2017)

14. Gamboa Becerra, Diedre. Alejandra PizaDe la voz ajena al silencio poetíco:

https://repository.javeriana.edu.co/bitstream/handle/10554/14947/Bec erraGamboaDiedre2014.pdf;sequence=1 (2014)

15. Haydu, Susana. Alejandra Pizarnik: Evolución de un Lenguaje Poético. Colección: INTERAMER, Número: 52, 1996. Capitulo IV, Textos principales: Evolucion de metaforas, Los trabajos y las noches Disponible en: http://www.educ oas.org/P ortal/bdig ital/co nteni do/in tera mer/ intera mer_52/index.aspx 
16. Moratiel, Virginia. "Cuando la muerte araña el alma: Alejandra Pizarnik" Disponible en: https://elvuelodelalechuza.com/2017/12/03/cuando-la-muerte-aranael-alma-alejandra-pizarnik/_(31/ 12/2017)

17. Perez, D. Carlos. "Alejandra Pizarnik: textos de locura y suicidio". Disponible en: http://javierdiazgil.blogspot.com/2007/05/blogpost.html (29/05/2007)

18. Pizarnik, Alejandra. Poesia Completa. Disponible en: https://sergiomansilla.com/revista/descargar/pizarnik_alejandra__poesia_completa.pdf_(1955 - 1972)

19. Paz, Octavio. Arbol de Diana, Poesia Completa. Disponible en: https://sergiomansilla.com/revista/descargar/pizarnik_alejandra__poesia_completa.pdf_(1962)

20. Raud, Niina. "The poetic text analysis study guide was composed": Disponible en: https://narva.ut.ee/eope/sl_analysis_of_poetic_texts/some_principles_of_versification.ht $\mathrm{ml}$ (2012)

21. Tarazona Hutardo, Alejandra. "La obra (in)completa de Alejandra Pizarnik: un acercamiento a su obra inédita a partir de Otoño o los de arriba". http://revistas.pucp.edu.pe/index.php/lexis/article/view/13438 Revista Lexis, Vol. 39, Núm. 1. 2015, p. 200.

22. Zapata Estrada, Pedro Arturo."Poetas malditos: Lucidez y rebelión", Revista Quitasol N 4, Bello, Colombia, Abril de 2008, p. 94. 